\title{
Maintaining Mental Health during COVID-19 Pandemic
}

\author{
Arshiya Masood Siddiqui ${ }^{1}$, Arun Singh ${ }^{2 *}$ and Dvijendra Nath ${ }^{3}$ \\ ${ }^{1}$ Professor \& Head, Department of Community Medicine, Government Medical College, Orai, \\ Jalaun, India \\ ${ }^{2}$ Professor \& Head, Department of Community Medicine, Rohilkhand Medical College, Bareilly, \\ India \\ ${ }^{3}$ Professor, Department of Pathology, Principal \& Dean, Government Medical College, Orai, \\ Jalaun, India
}

\section{Review Article \\ Volume 4 Issue 4}

Received Date: July 15, 2020

Published Date: August 12, 2020

DOI: $10.23880 /$ eij-16000157

*Corresponding author: Arun Singh, Professor \& Head, Department of Community Medicine, Rohilkhand Medical College \& Hospital, Bareilly International University, Bareilly, Uttar Pradesh, PIN: 243006, India, Tel: +91-9956008272; Email: arunspm@ gmail.com

\section{Abstract}

New diseases have always been emerging and re-emerging and created panic and chaos among general public since ancient times. The current pandemic due to SARS-CoV-2 threatening the whole human race and due to this COVID-19 pandemic the fears, anxieties, stressors are dominating the communities of the globe. All media and channels have been discussing about all the kind of hopelessness like unavailability of effective treatment protocol, antiviral drugs and vaccines, there is panic all around the world. Among these uncertainties many institutions have been looking for the new ray of hope in the form of new antiviral drugs and vaccines against COVID-19. The humanities had faced such types of pandemics in the past and won the battle against these. Humanity and disease have always existed side by side15. Various pandemics e.g. influenza, plague, cholera and other infectious diseases have terrified the human from time to time but every time they have survived, won the battle, learnt a lesson and become better, stronger and creative. Until we get effective antiviral drugs and vaccines against COVID-19, the team PSM (Physical distancing, Sanitization of hands, equipment, surfaces, Masks) will work constantly against the COVID-19 and will play key role in stopping the transmission.

Keywords: Physical Distancing; Sanitization of Hands; Equipment; Surfaces; Masks

\section{Introduction}

Pandemics are not new to human societies. Scientists at different ages have been shocked, baffled and have struggled to cope with various deadly infectious diseases throughout centuries [1]. One such pandemic of $21^{\text {st }}$ century is COVID19 pandemic caused by SARS-CoV-2 which has changed the world suddenly. First case of this novel corona virus occurred in Wuhan, China in December 2019. In January WHO declared this outbreak by the new corona virus as Public Health Emergency of International Concern. WHO stated that there is risk of COVID-19 spreading to other countries around the world. In March 2020, WHO made the assessment that COVID-19 can be characterized as a pandemic [2].

After $1^{\text {st }}$ case in Wuhan city in December, the $1^{\text {st }}$ confirmed case in India was on $30^{\text {th }}$ January a student belonging to Kerala's Thrissur district who had returned for vacation from Wuhan city. Two subsequent cases reported on $2^{\text {nd }}$ and $3^{\text {rd }}$ February were also students returned from China in Kerala. On $2^{\text {nd }}$ March the Union Health Ministry reported two more cases; A 45year old man in Delhi who travelled back from Italy and a 24year old engineer in Hyderabad who had a travel history with UAE [3]. Since then cases kept on increasing. 


\section{Epidemiology International Journal}

When cases reached approximately 500 , it became necessary to place lockdown to slow the spread. On 24 $4^{\text {th }}$ March 2020, the Government of India under honorable Prime Minister Narendra Modi ordered a nationwide lockdown for 21days limiting movement of the entire 1.3billion population of India as a preventive measure against the COVID-19 pandemic [4]. Lockdown has disrupted routines and confined people to one space. The world seemed to turn upside down. People became lonely, confused and panicked.

\section{Effects of Lockdown and Pandemic on People}

- Fear of unknown/uncertainty

- Feeling of loneliness and those who were already feeling lonely, their conditions exacerbated

- Fear of loss of wages/earning

- Fear of getting infection and infecting their loved ones

- Stigma of isolation and quarantine

- Worsening of chronic diseases and mental disorders

- Fear of not getting proper care for other essential health needs

- Problem of "infodemics".

\section{Effects on Different Groups}

Children and Adolescents: Children and adolescents face an enormous disruption of their lives. They are likely to be experiencing various types of worries, anxieties, fears and stresses similar to those experienced by adults. Their specific stressors are closure of school and distance from schoolmates. Because of closure of school they no longer have the sense of structure and stimulation that is provided by school environment and now they have fewer opportunities to be with friends and get that social support that is essential for their mental wellbeing [5]. Poor children bear disproportionate burden of this global crisis. Closure of schools may also result in loss of meals provided by schools. For some of them school may be an escape from unhealthy environment of home. Many of them may not return to school again. For adolescents who are in transitional phase of life this crisis may result in disruption of their passage of rite. As they seek independence and relate more to their peers than parents, confinement at home may have adverse psychosocial outcomes and risky behavior in them.

Adults: Along with other stressors more specific stressors for adults is financial breakdown. Issues related to parental unemployment and loss of family income are echoed in all family members including children and adolescents.

Elderly People: We can say them older adults, during this particular situation/ scenario they may feel that they are in isolation and are alone and due to cognitive decline and dementia they may become more anxious, angry, stressed, agitated and withdrawn during the outbreak.

People Living with Disability: There are more than 1 billion people living with disabilities (PLWD) worldwide [6]. PLWD including physical, mental, intellectual and sensory disabilities are less likely to access health services, and more likely to experience greater health needs, worse outcome and discriminatory laws and stigma. COVID-19 threatens to exacerbate these disparities, particularly in low income and middle income countries where $80 \%$ of PLWD reside, and capacity to respond to COVID-19 is limited [7].

Effect of Compromised Essential Services on all Areas: Essential services for all areas include reproductive, maternal, new-born and child health, prevention and management of communicable diseases, treatment for chronic diseases to avoid complications and addressing emergencies [8]. It is likely that health seeking may be deferred because of social/ physical distancing requirements or community reluctance owing to perceptions that health facilities may be infected [9]. People are depressed unable to figure out where to go in time of need.

\section{Corona warriors: Health care providers and frontline workers [10]:}

- Novel nature of SARSCoV-2.

- Inadequate testing.

- Limited treatment options.

- Insufficient personal protective kits.

- Extended work hours/workload.

- Concern about getting infected and infecting and caring for their loved ones.

- Emotional trauma of seeing people dying before their eyes.

- Emotionally and ethically fraught resource allocation decision.

- There is risk of stigmatization and discrimination by society for whom they are fighting.

This period of confinement especially if indoors and in small spaces could lead to higher risk of Vitamin D deficiency, mental health issues, myopia and increased risk of respiratory infections [11].

\section{How to Recognize Mental Health Problems: Observe the following [12].}

- Changes in sleep pattern

- Difficulty in sleeping and concentrating

- Worsening of health problems

- Increased use of alcohol, tobacco or drugs

- Loss of appetite

- Abnormal behavior

How to Address Mental Health Problems: Understand coping mechanism, insight, tools and techniques. 


\section{Epidemiology International Journal}

Coping Mechanism: Kubler-Ross five stages model. Kubler Ross, a Swiss American psychiatrist introduced this model inspired by her work with terminally ill patients. She described five stages of grief in her book "On Death and Dying" in 1969. These stages represent the normal range of feelings people experience when dealing with change in their lives or in any tragic event. These five stages are

1. Denial: "I can't believe it", "This can't be happening", "Not to me"

2. Anger: "Why me? It's not fair", "No!", "I can't accept it"

3. Bargaining: "Just let me live to see my children graduate", "I will do anything if you give me more time, a few more years"

4. Depression: "I am so sad why bother with anything?" "What's the point of trying".

5. Acceptance: "It's going to be OK", "I can't fight it, I may as well prepare for it"

Kubler Ross called them normal reactions, defence mechanism or coping mechanism that we need to move through in order to manage change. She said that these stages can last for different period of time or will replace each other or exist side by side. Ideally it would be good to think that we will reach the phase of "Acceptance" while managing changes but some people get stuck in the stages and find it difficult or impossible to move on. Although these stages are descriptive not prescriptive, they do provide an insight into coping mechanism of any tragic event [13].

When we translate this model to COVID-19, we see

1. Denial: This can't be happening? Are you serious? The flu kills more people every year? It's business as usual. I am not buying into hype

2. Anger: This is ridiculous. This is going to cost us millions. What are these morons doing? Why didn't anyone get ahead of this?

3. Bargaining: i.e. making a trade-off. This is painful but for the best. A temporary closure is costly but will save lives and get back to normal more quickly. I may only get mild symptoms but if my grandma was to get this, she'd be a goner.

4. Depression: What's the use, we are all going the get this virus anyhow? How will I pay my rent? My business can't survive a prolonged shutdown.

5. Acceptance: Exploring options and moving on. This is what's happening and therefore this is what we need to do in response. We act fast and we act decisively in order to save lives [14].

Insight: Although COVID-19 pandemic seems to be the largest pandemic of our lifetime but it is not the first time, it happened in the past and may happen in the future. Humanity and disease have always existed side by side [15]. Various pandemics e.g. influenza, plague, cholera and other infectious diseases have terrified the man from time to time but every time he has survived, won the battle, learnt a lesson and become better and stronger. New diseases are always emerging and re-emerging. Marie curie said, "Nothing in life is to be feared, it is only to be understood. Now is the time to understand more, so that we may fear less". Fear is focusing and energizing. Creativity is a defence against feeling helpless. People are more creative in a crisis because urgent and important are better aligned in a crisis. History is a witness that whenever there is a crisis, there is always a creativity surge. This is what is happening now, creative solutions (may not be very perfect) are coming from every walk of life e.g. medical communities, government and policy makers, data scientists, business communities, teachers, parents and ordinary man etc. Very soon we will control this pandemic as we have always done [16].

\section{Tools and Techniques}

As COVID19 is a new viral disease caused by novel corona virus, there are gaps in understanding of natural history of disease. There is inundation of information both true and fake from various portals of information which is baffling and confusing to people. So the most vital fact is to provide them with correct information; what we know and what we don't know, the nature of disease, how it is transmitted and how to prevent and control. People should be guided how to remain safe, secure, hopeful and cool in this collective crisis. Various myths and misconceptions regarding COVID-19 must be busted.

\section{Following Measures are Recommended}

- Getting information from reliable sources only. Minimize watching, listening and reading news about COVID-19 that causes you to feel anxious or distresses. Seek information at specific time during the day once or twice [2]. Refer affected people as "People who have COVID-19" or "People as being treated for COVID-19" not as "COVID-19 cases" [17].

- Be empathetic. Do not attach the disease to any particular ethnicity or nationality.

- Check by telephone on neighbors or people in your community who may need some extra assistance

- Honour carers and health care workers supporting people affected with COVID-19

- Try and use helpful strategies such as ensuring sufficient rest and respite during work, eat healthy food, engage in physical activity and stay in contact with family and friends.

- Give young people the love, attention and care they need to resolve their fears, anxieties and stresses and be honest with children by explaining what is happening in a way that they can understand, so what even if they 


\section{Epidemiology International Journal}

are too young to understand. Parents also need to be supported in managing their own stressors so that they can be model for their children. Helping children to find ways to express themselves through creative activities, and providing structure in the day-if that is possiblethrough establishing routines, particularly if they are not going to school anymore, can be beneficial [18].

- Take special care of vulnerable group like elderly, disabled and sick people. Stay connected and maintains social work, Avoid listening to or following rumours that make you feel uncomfortable. Keeping each other safe and connected is everyone's responsibility. Together we can beat COVID-19 [5].

- Give psychological first aid [19].

- Psychological first aid: is a humane, supporting response to fellow being who is suffering and may need support. It is an acute intervention of choice when responding to psychosocial needs of children, adults and families affected by disaster and terrorism. It involves following 7 themes.

- Assess needs and concerns

- Help with basic needs (e.g. food, water and information)

- Listen but don't pressure them to talk.

- Comfort them and help them feel calm

- Connect them to information, services and social support

- Protect people from further harm.

- Provide practical care and support.

Manage your own stress. Take rest and reflect. Don't enter the risky areas without protection. "Prepare-LookListen-Link-Rest-Reflect"

\section{Conclusion}

The impacts of COVID-19 pandemic and accompanying lockdown effects have resulted in fears about the unknown, insecurities, anxieties, confusions and feeling of isolation and the loss of work and wages, school closures, disruption of essential services and shortages of resources have further deteriorated the health of human beings in terms of the physical, mental, social, spiritual, vocational and emotional dimensions. These health related problems may be reflected in unhealthy behavior like increased substance abuse, non-compliance of instructions, antisocial behavior and increase crime due to increasing poverty. So it is high time to address mental health issues and train and orient health care providers and other front line workers regarding these issues. Worries and miseries of the people must be acknowledged and addressed optimally and urgently. Containment and mitigation activities go hand in hand. Saving lives and reviving livelihood is vital. Some of the people may succumb to this crisis but many will develop resilience and will become stronger. Be kind, stay safe and stay secure.

\section{References}

1. Erkoreka A (2009) Origins of the Spanish Influenza pandemic (1918-1920) and its relation to the First World War. J Mol Genet Med 3(2): 190-194.

2. (2020) Mental health and psychosocial considerations during the COVID-19 outbreak. World Health Organization, pp: 1-6.

3. (2020) Timeline of the Covid 19 Pandemic in India.

4. (2020) Covid-19 pandemic lockdown in India.

5. (2020) Mental health and psychological resilience during the Covid-19 pandemic. World Health Organization.

6. Armitage R, Nellums LB (2020) The COVID-19 response must be disability inclusive. Lancet Public Health 5(5): 257.

7. (2019) Prioritising disability in universal health coverage. The Lancet 394(10194): 187.

8. (2020) Enabling Delivery of Essential Health Services during the COVID-19 Outbreak: Guidance note, pp: 1-19.

9. (2020) Guidance Note on Provision of Reproductive, Maternal, Newborn, Child, Adolescent Health Plus Nutrition (RMNCAH+N) services during \& post COVID-19 Pandemic.

10. Pfefferbaum B, North CS (2020) Mental Health and the Covid-19 Pandemic. N Engl J Med.

11. Lee J (2020) Mental health effects of school closures during COVID-19. Lancet Child Adolesc Health 4(6): 421.

12. (2020) Minding the minds during Covid-19.

13. Connelly M (2020) Kubler-ross five stages model. Change Management Coach.

14. (2020) How to identify the stages of grief in Covid-19 message.

15. (2020) Infectious Disease Emergence: Past, Present, and Future.

16. Boyes A (2020) Alice Boyce PhD Why are people more creative in a crisis?. Psychology Today.

17. (2020)WHO self-help intervention reduces psychological distress in humanitarian crisis situation. World Health Organization. 


\section{Epidemiology International Journal}

18. (2020) Statement-Physical and mental health key to resilience during COVID-19 pandemic. World Health Organization.
19. Singaravelu V (2020) Psychological First Aid: Field workers Guide. 